\title{
Strategies and Tactics in Gaining Public Opinion
}

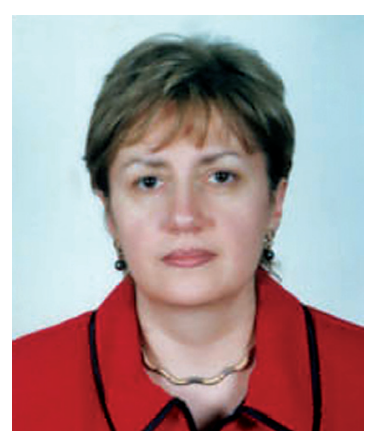

Armine Simonyan

Towadays the growing interest in political discourse is quite evident. Such questions as: - How is political power won and lost? And how crucial is the role of language in ups and downs of political life? - can be better understood through discourse analysis. The analysis through the strategies and tactics used in political campaigns highlights new directions in language study regarding political discourse as a tool of manipulation and persuasion (Johnson-Cartee, Copeland 2004:146).

The research is carried out based on American political discourse. The United States managed to create a democratic country with concepts of truth and respect regardless of a person's nationality or ethnic background. The correct understanding of citizenship, solidarity, and national consciousness were implemented in Americans' minds and souls by professional politicians (Chilton 2004:11).

Language is a weapon and an important tool in attracting public support. We would like to show how the American politicians use the English language and how it demonstrates its powerful creative abilities in gaining public support. Traditionally, political clashes take place between the members of two main parties. But what happens when two politicians represent one single party?

An investigation of the transcripts of Democratic presidential debates between Senators Hillary Clinton and Barack Obama adds new content information to the flourishing field of political linguistics.

The reason for selecting these debates is quite simple. The candidates, as members of the same party, share a number of common and unique features. For example, they have the same target audience who traditionally has adopted the democratic principles of their party. At the same time there must be crucial differences between them - it is the first time in the history of the United States that the candidates for the Presidency are an African American and a woman.

An analysis of the transcripts of presidential debates brought us to the conclusion that the two main strategies utilized by both speakers are the strategy of positive selfpresentation and negative other-presentation.

The polarization between Us and Them, and the different ways of expressing negative and positive opinions are enhanced by the choice of various language units.

The 2008 Democratic Party Presidential debates in the US are vivid examples of this polarization. The positive self-presentation interwoven with national pride and glory are combined with the portrayal of others which are downplayed by the candidates with strong determination to reveal the difference and threat which they symbolize. 
Let's give an example demonstrating the strategy of positive self-presentation by quoting Hillary Clinton at the Democratic Party Presidential Debate in Utah.

"...I'm running because I think I'm the most qualified and experienced person to hit the ground running in January 2009”.

Barack Obama in LA said,

"I am confident that we can solve any problem and we can fulfill the destiny that America wants to see, not just next year, but in many years to come”.

This strategy on Hillary Clinton's part is realized by parallel repetition of the pronoun "I", which in combination with the superlative degree of adjectives (the most qualified and the most experienced), intensifies the idea and strengthens its impact on the listener.

It goes without saying that personal pronouns are extremely important in political discourse. If Hillary Clinton uses the personal pronoun "I", Barack Obama prefers the combination of "I" and "We" focusing the attention of the audience not only on himself but also on the audience, emphasizing the positive characteristics of the whole nation and regarding himself and the American nation as a single entity.

In this passage we can solve any problem and we can fulfill the destiny the first person plural pronoun we conceptualizes group identity, distinguishing insiders from the outsiders. The use of the modal verb can shows the speaker's attitude towards the action indicated by the infinitive. The author wants to point out his strong intention, his ability to realize his future plans.

Emphasizing positive characteristics of oneself, the politicians often appeal to the illustration of the issue of national identity which is intended to target the broadest number of supporters. This is the reason why both candidates of the Democratic Party pay special attention to the symbols of national identity. This is reflected either in the beginning or the end of their speeches. The sense of national identity is represented in the phrases "the America people, my fellow Americans, all Americans".

The strategy of positive self-presentation has been used by politicians to prove their professionalism and competency as they both experience attacks, one for being a woman and the other on the topic of racism..

During the presidential debate in Utah Hillary Clinton was asked:

"Hello, my name is John McAlpin. I'm a proud serving member of the United States military. I'm serving overseas. This question is to Senator Hillary Clinton. The Arab states, Muslim nations, believe its women as being second-class citizens. If you're president of the United States, how do you feel that you would be taken seriously by these states in any kind of talks, negotiations, or any other diplomatic relations?"

Hillary Clinton answered: "Thank you John, and thank you for your service to our country. You know, when I was first lady, I was privileged to represent our country in 82 countries. I have met with many officials in Arabic, and Muslim countries, I have met with kings and presidents and prime ministers and sheiks and tribal leaders. And certainly, in the last 
years during my time in the Senate, I have had many high-level meetings with presidents and prime ministers in Iraq, Afghanistan, Kuwait, Pakistan and many other countries. ... It would be quite appropriate to have a woman president deal with the Arab and Muslim countries on behalf of the United States of America".

Senator Clinton starts her answer by expressing her appreciation using the tactics of positive politeness. In this way she demonstrates her gratitude putting stress on the existence of common ground between them. Afterwards, to enhance credibility, she enumerates numbers of meetings with the leaders of many countries to sound persuasive and convincing.

Speaking about racism Senator Obama quotes the Bible, seeking to have a strong aesthetic impact on the listeners.

The strategy of positive self-presentation backed by famous quotations relates politician's speech to the sphere of objectivity.

“... what is called for is nothing more, and nothing less, than what all the world's great religions demand - that we do unto others as we would have them do unto us. Let us be our brother's keeper, Scripture tells us. Let us be our sister's keeper. Let us find that common stake we all have in one another, and let our politics reflect that spirit as well".

The tactics of citation used by the politician makes his speech colorful. There is constant interaction between the linguistic units and their desirable effect on the audience. Inverted constructions, anaphoric repetition of the phrase let us unite the audience and enhance its positive effect. By the repetition of the word nothing the politician shows how little is demanded to eliminate race discrimination among the people.

Humor is recognized as another vital tactics in the process of political campaigning; it sustains interest in debates and has relaxing effect on the audience.

When blamed for being dishonest: seeking help from the advisers of Bill Clinton, Barack Obama tried to stop inappropriate accusations answering in a humorous way.

"Hillary, "I look forward to you advising me..."

If we try to interpret the use of humor in this context we may conclude that humor has rather condensed, double meaning in this context. First Senator Obama admits that Hillary Clinton was the most valuable adviser to President Clinton and, second, in this campaign Barak Obama considers himself to be the likely President and would like to see Hillary Clinton as his adviser.

Personal pronouns play a crucial role in political discourse. The distinction between the pronoun you in the previous example "You know, when I was the first lady" and the pronoun you in "I look forward to you advising me" according to grammarians is hardly significant. But discourse analysis reveals that in the first case we deal with the indefinite you. The speaker implies to address simultaneously both the audience and the young officer, whereas in the second sentence we come across direct you, Barak Obama directly addresses his opponent.

Indefinite $\boldsymbol{y o u}$ is observed also in the following example "You should vote for me", in this case the speaker addresses only the audience. High frequency of indefinite you is 
explained by the speaker's appeal to the majority and his desire to regard the audience as an indispensable entity.

In the above-mentioned examples the strategy of positive self-presentation takes the form of individual impression management, but when the politicians try to represent their own party the same strategy takes the collective form of presentation. If an individual becomes a public figure, for the sake of the party he belongs to he adopts the obligation or commitment to avoid mentioning negative sides that could damage the positive image of their party. Both Senator Clinton and Senator Obama are loyal to the principles of the Democratic Party they belong to. In this respect, the positive self-representation of the Democratic Party is manifested on the issues which are abandoned by the majority of the population. Ideas that are intended to gain public support. are: the provision of proper education, medical care, discrimination against minorities and women, freedom from injustice, religious intolerance and eventually the termination of the war in Iraq.

The strategy of self-representation as the first constituent of the dichotomy is tied up with its second half i.e. with the strategy of negative other-representation.

There is evidence that individuals are inclined to pay more attention to negative information. The policy of bringing out negative traits of their opponents and the complete denial of their own is realized in assessments about others.

The candidates may regard as "others" first of all their common enemy, the Republican Party, and each other in these particular debates.

Negative evaluation of their ideological rival is based on the common ground of the concepts which are shared by the members of the Democratic Party.

If we leave aside common enemies, we shall come to the battlefield where candidates demonstrate strong performance and expose an extremely vast scope of issues, sometimes they even explore personal matters.

Clinton's sharpest attack on Obama came when she accused him of plagiarism, of borrowing lines from a speech of his co-chairman.

"If your campaign is going to be about words, they should be your own words. Lifting whole passage isn 't change you can believe in, it's change you can Xerox".

The semantic strategy of Negative Other representation is enhanced by the repetition of linguistic units and the use of modal verbs. In political discourse the use of modal verbs indicates the degree of commitment to truth, to ideas the utterer holds or represents.

The strategy of negative other representation is demonstrated in another example as well. Hillary Clinton, criticizing Barack Obama said: "You know, Senator Obama, it is very difficult having a straight-up debate with you, because you never take responsibility for any vote, and that has been a pattern."

The semantic strategy of negative other representation is demonstrated through the tactics of description. Senator Obama is described extremely negatively. He is the person who deviates from straight-forward questions and is irresponsible.

The same strategy was used by Barack Obama too. He said:" Senator Clinton has, in her campaign at least, has constantly sent our negative attacks on us, e-mail, robo-calls (prerecorded messages), fliers, television ads, radio calls, and we haven't 
whined about it, because I understand that's the nature of this campaign".

Barack Obama in this case has appealed to the tactics of argumentation. The strategy of negative other representation is backed up by statistical evidence. The enumeration of these facts creates a negative impression on the audience. It has a persuasive effect and strong impact on the listener.

In some cases the strategy of negative other-presentation is combined with the strategy of positive self-presentation. During the Iowa Caucases Hillary Clinton said. "Some believe you get change by demanding it. Some believe you get it by hoping for it. I believe you get it by working hard for change. That's what I've done my entire life."

Through the tactics of contrast expressed in the passage Hillary Clinton wants to bring out her vision of changes. The contrast is created by the verbs characterizing the opponents (to demand, which presupposes a certain portion of aggressiveness and the verb to hope, a verb with a positive connotation but with some traits of idleness or joblessness. The verb to work characterizes Hillary Clinton. Used as a stylistic device, anaphoric and epiphoric repetition of linguistic units acquire not only emotive charge but they also aim at logical emphasis, focusing the attention of the audience on the keyphrases of the passage. Furthermore, the repetition of similar sound combinations or rhyming is observed in this passage too.

And one of the strongest moments in the Clinton's campaign was in explaining the role of gender. "People are not attacking me because I'm a woman, they are attacking me because I am ahead". She characterizes her opponent's use of the word attack of negative connotation. Hillary Clinton doesn't want to focus the attention on the problem of gender as if it doesn't exist. She is projecting to her supporters the image of a person who is ahead in this campaign. Here again we face the combination of both semantic strategies. The internal rhyming consolidates the ideas expressed in the sentence.

In my opinion this quotation sums up Hillary Clinton's platform during these debates: "It did take a Clinton to clean up after the first Bush, and I think it might take another one to clean up after the second Bush".

Political discourse is not just words, sentences or ideas expressed by an ordinary citizen, it is an influential tool that might cause concrete forms of action. Focusing on crime, violence, terrorism, and the negative properties of others politicians must be, to some extent, exquisitely accurate, as inappropriate definitions can easily lead the audience either to horrors of quarrels and clashes or to the disillusionment of citizens and their loss of interest towards politics itself.

\section{References:}

1. Chilton, Paul (2004) Analysing Political Discourse: theory and practice. London \& New York: Routledge, Taylor and Francis Group.

2. Johnson-Cartee, Karen, S.; Copeland, Gary, A. (2004) Strategic Political Communication: rethinking social influence, persuasion, and propaganda. Maryland: Rowman \&Littlefield Publishers, Inc. 


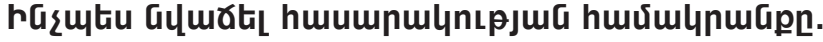

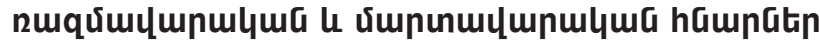

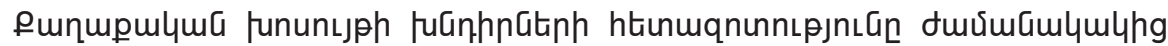

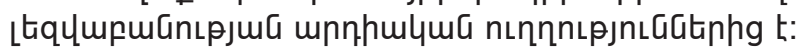

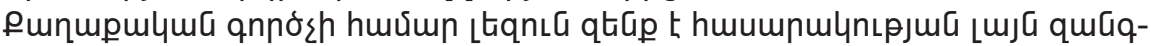

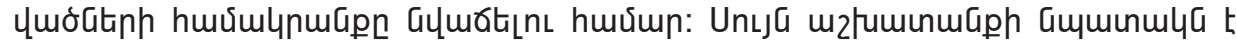

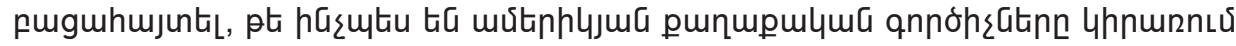

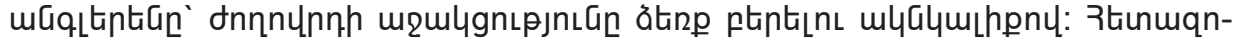

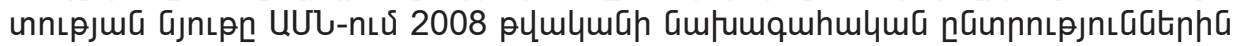

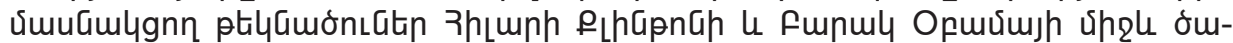

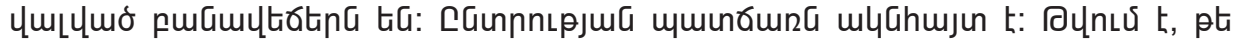

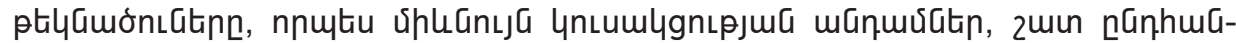

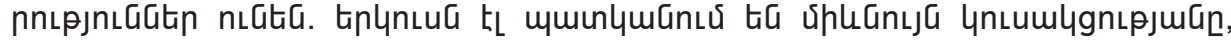

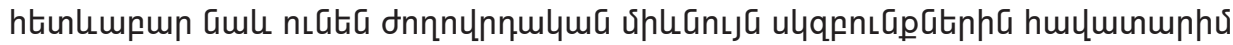

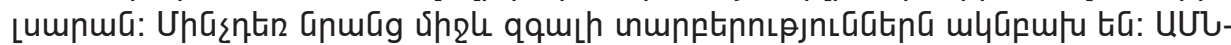

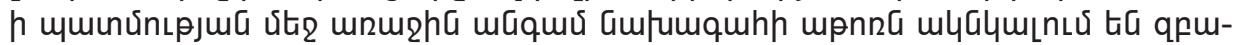

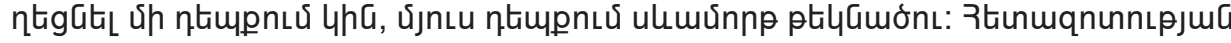

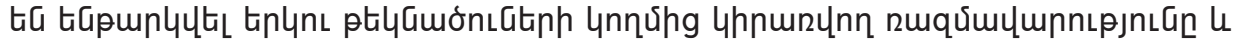

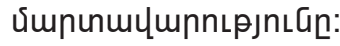

